Geografia e Ordenamento do Território, Revista Eletrónica

Centro de Estudos de Geografia e Ordenamento do Território

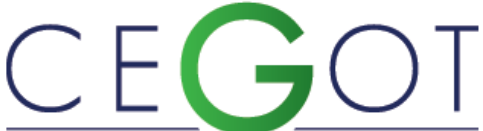

Centro de Estudos de Geografia e Ordenamento do Território http://cegot.org

ISSN: 2182-1267

Passos, M.

Programa de Pós-Graduação em Geografia da UNESP, campus de Presidente Prudente/SP-Brasil mmpassos86@gmail.com

Souza, R.

Programa de Pós-Graduação em Geografia da UNESP, campus de Presidente Prudente/SP-Brasil

reginaldogeo@hotmail.com

\title{
A paisagem, uma ferramenta de análise das mudanças socioambientais no eixo da rodovia BR-163: de Cuiabá/MT a Santarém/PA ${ }^{1}$
}

Referência: Passos, M. \& Souza, R. (2013). A paisagem, uma ferramenta de análise das mudanças socioambientais no eixo da rodovia BR-163: de Cuiabá/MT a Santarém/PA. Revista de Geografia e Ordenamento do Território, n. 3 (Junho). Centro de Estudos de Geografia e Ordenamento do Território. Pág. 171 a 196.

\footnotetext{
${ }^{1}$ Artigo resultante do desenvolvimento do Projeto de Pesquisa apoiado pela Fundação de Amparo à Pesquisa do Estado de São Paulo-FAPESP (Processo no 2010/51074-6). O Projeto de Pesquisa “A paisagem, uma ferramenta de análise para o desenvolvimento sustentável de territórios emergentes na interface entre natureza e sociedade" tem como recortes geográficos: (a) Sudoeste do Pará: Paisagem e biodiversidade, (b) Sudoeste do Mato Grosso: Paisagem e dinâmica agrícola e (c) Pontal do Paranapanema: Paisagem e recursos territoriais. No entanto, nesse artigo vamos abordar tão somente o Sudoeste do Pará, mais especificamente o eixo da rodovia BR-163, no trecho entre a divisa dos estados do Mato Grosso com o Pará (Serra do Cachimbo) e a cidade de Novo Progresso/PA.
} 


\title{
Resumo
}

Este artigo objetiva mostrar como a paisagem é um indicador dos processos de antropização dos meios, e em que medida ela é uma ferramenta de análise pertinente das dinâmicas espaciais na interface natureza-sociedade. A espacialização das paisagens-indicadoras a partir da utilização de imagens de satélite é um ponto de partida pertinente/satisfatório à realização de diagnósticos paisagísticos para melhorar o conhecimento dos territórios e ajudar a tomada de decisão em matéria de políticas de desenvolvimento sustentável? O objetivo maior desse projeto é, a partir de um guia metodológico comum, desenvolver, segundo os contextos regionais, abordagens metodológicas específicas a fim de testar a paisagem como ferramenta para avaliação da sustentabilidade (paisagens-indicadoras).

Palavras-Chave: Paisagem, Amazônia, Geoprocessamento, Desenvolvimento sustentável.

\begin{abstract}
This article intends to demonstrate how the landscape is an indicative of anthropogenic transformation in the environment, as well what extent it is an appropriate tool to analysis of spatial dynamics in the interface of nature-society. Is the spacialization of indicative-landscapes by satellite images a satisfactory/interesting start point to implementation of environmental diagnostics to improve the knowledge of territories and help decision-making on sustainable development? Based on a common methodological guide and different regional contexts, the main objective of this project is develop specific methodologies to test the landscape as a tool by evaluation of sustainability (indicative-landscapes).
\end{abstract}

Keywords: Landscape, Amazonia, Geoprocessing, Sustainable development. 


\section{Introdução}

Se há um contraste de paisagem, há, também, um contraste políticoadministrativo. Para conhecer a geografia física é preciso conhecer os problemas sociais, econômicos, administrativos...

O Brasil chama atenção pela diversidade e rapidez das mudanças socioeconômicas e ambientais que o afetam. Há regiões em pleno processo de emergência, como a do arco de colonização agrícola na Amazônia - Vale do Guaporé-Chapada dos Parecis e Sudoeste do Pará/Novo-Progresso -, onde as alterações são muito notáveis. Esta região está na mídia nacional e internacional pelos impactos dos desmatamentos sobre a regressão da biodiversidade. Outras regiões têm, ao contrário, uma longa história em matéria de povoamento e ocupação. É o caso do Sudoeste do Estado de São Paulo, mais conhecido como "Pontal do Paranapanema", espaço de conflito e de redefinições socioambientais recentes, por vezes contraditórias e onde a gestão dos recursos naturais se apresenta de maneira crucial.

Estas diferentes áreas apresentam meios complexos, onde a geodiversidade (Grenier, 2000) se erode ao contacto de fortes mutações naturais e sociais. Os ecossistemas variados dessas regiões são confrontados com transformações aceleradas devidas a organização espacial e aos tipos de explotação muito agressivos. No arco da colonização agrícola, 0,5 a 1 \% da floresta amazônica passa do status de ecossistema natural para o de paisagem rural, sem que se observe sistematicamente uma melhora significativa dos indicadores de desenvolvimento humano (IDH).

Na Amazônia, a combinação de fatores biofísicos de uma parte, e as múltiplas iniciativas e ações humanas motivadas pelos interesses econômicos de outra parte, conduzem a grandes dificuldades de acompanhamento, em tempo real, do conhecimento científico desses meios, e cuja identificação das políticas públicas permite engajar esta região na via do desenvolvimento sustentável. É, sem dúvida, nesta via que o Brasil deseja se orientar depois dos acordos assinados durante a Conferencia Internacional das Nações Unidas sobre Meio Ambiente e Desenvolvimento Humano - a Eco-92. A noção de sustentabilidade, que introduziu a reflexão e a ação em matéria de desenvolvimento, se apresenta muito clara: a 
referência à lógica de progresso das sociedades humanas, coloca a ênfase sobre a necessária articulação entre a viabilidade econômica das formas tomadas por este desenvolvimento, sua capacidade de não colocar em perigo os recursos ambientais sobre os quais ele se funda, e o caráter equitativamente benéfico de seus efeitos sobre os diferentes grupos sociais (Conferência Mundial sobre o desenvolvimento sustentável, 2002). É, portanto, neste "conceito" que as questões de sustentabilidade devem ser entendidas, ou seja, integrando as questões que correspondem aos meios naturais e às dinâmicas sociais. Lembramos que, não se trata de identificar e de proteger os meios frágeis de um lado e de outro de "sacrificar" regiões em nome de um desenvolvimento econômico e social, mas, sobretudo, de conservar os meios nos quais as sociedades possam se desenvolver em plena coerência.

\section{A paisagem-indicadora no debate das questões ambientais}

$\mathrm{Na}$ formação de um pensamento conjuntivo sobre as questões ambientais, valorizamos o estudo da paisagem como modo de estabelecer um elo entre o meio ambiente e o território e analisar os impactos antrópicos na natureza. A paisagem não deixa de ser isto, também: um indicador das relações, históricas e atuais, das sucessivas sociedades com o meio ambiente que transforma.

Embora a noção de paisagem traga em si uma forte carga de subjetividade, por outro lado, na investigação científica voltada ao meio ambiente, não há como desconectá-la da materialidade dos contornos do espaço geográfico, suas formas, seus elementos naturais e artificializados. Se a verdade de uma paisagem consiste tanto no que ela esconde quanto naquilo que mostra (Donadieu \& Périgord, 2005, p. 84), então, ela é uma chave para a compreensão das relações subjacentes a uma determinada organização espacial.

Entre a realidade visível e as imagens construídas, Donadieu e Périgord nos falam sobre três etapas de elaboração de uma paisagem:

- Celle de l'image peinte qui represente une portion d'espace terrestre (l'étape pittoresque); 
- Celle de l'image de la spatialisation des activités humaines, répresentation de la relation de l'homme à un espace (l'étape géographique);

- Enfin, celle de l'image de territoire qui permet à l'homme de s'identifier à um espace, par sa pensée et son action (l'étape identitaire). (2005, p. 33)

A paisagem se constitui na confluência do que a sociedade produziu no passado e produz no presente. Sintetiza divergências e convergências: pode explicitar o descompasso das relações sociedade-meio ambiente e os mecanismos de depredação da natureza, mas, ao mesmo tempo é a forma, entre as mais evidentes, que as sociedades possuem para visualizar os desdobramentos negativos de suas próprias ações (e planejar soluções).

Nós optamos em desenvolver a nossa problemática de pesquisa em torno da noção de "paisagem" - em primeiro lugar pelo caráter aglutinador que lhe confere. Bertrand (2002) edificou as bases conceituais da paisagem como meio de fazer dialogar as ciências naturais e as ciências sociais em torno de questões socioambientais. Deffontaines (1998) deu um caráter concreto e operatório à abordagem paisagística para que ela traduza e revele os modos de funcionamento e de organização dos espaços, "a paisagem sendo o lugar onde se inscrevem indicadores visuais práticos num meio dado". Assim, a entrada pela paisagem foi retida desde que o interesse em conjugar uma abordagem naturalista, indicadora das dinâmicas biofísicas, a uma abordagem territorial sobre a apreensão pela sociedade dos recursos naturais cuja gestão depende, notadamente, da escolha e das orientações em relação com as dinâmicas socioeconômicas dos territórios considerados. A paisagem é, pois, o resultado material de um conjunto de interações entre processos físicos, processos ecológicos, processos sociais e processos culturais. Na verdade, ela é considerada como o "reflexo das relações entre o homem e seu meio ambiente" e aparece assim indissociável do conjunto das dinâmicas territoriais (Béringuier et al. 1999).

A paisagem adentra na ciência geográfica durante o século $\mathrm{XIX}$, concebida como "conjunto de formas que caracterizam um setor determinado da superfície terrestre" (Passos, 1988). A partir de então, sua abordagem também foi associada à dimensão objetiva numa perspectiva positivista/naturalista dentro das diferentes escolas (alemã, 
francesa, soviética e anglo-saxônica), buscando-se a análise de seus elementos para se chegar a visões de conjunto sobre os aspectos de uma dada porção do espaço.

Durante o século $X X$, notadamente com os desdobramentos da teoria dos sistemas na Geografia, a forma de abordagem paisagística passou por modificações importantes. De uma chave para a caracterização de áreas, a paisagem também se tornou um objeto de estudo em si, foco de modelos teóricos e metodológicos para aprofundar a compreensão sobre sua estrutura, funcionamento, evolução e o estabelecimento de tipologias para classificar os diferentes níveis de transformação dos meios naturais sob a influência ou o impacto direto das sociedades.

A modelização, com base na distribuição dos elementos constituintes de uma determinada paisagem e nas dinâmicas que produzem e alteram sua fisionomia, se faz presente na pesquisa em Geografia Física até os dias de hoje, inclusive permitindo a sistematização de informações e produção de toda uma cartografia baseada na espacialização de unidades e subunidades paisagísticas. Os avanços tecnológicos contribuíram diretamente para o desenvolvimento de procedimentos nesta área. $\mathrm{A}$ evolução dos instrumentos de sensoriamento remoto faz jus a estes avanços: desde as fotografias aéreas, imagens de satélite, aplicativos para o processamento de imagens até as câmeras fotográficas digitais e aparelhos do Sistema de Posicionamento Global que permitem registros mais precisos de informações diretamente no terreno.

Esta atual investida tecnológica, em termos de metodologias aplicadas à análise da paisagem, é um fato irreversível e, de certa forma, representa a evolução do tipo de enfoque que emergiu a partir dos anos de 1960 e, também, representa um salto qualitativo para a pesquisa ambiental. Sistemas técnicos são cada vez mais utilizados na captura e representação dos sistemas paisagísticos.

Ao falarmos de sistemas paisagísticos, explicitamente concordamos com as construções teóricas que valorizam o enfoque global como estratégia de compreensão dos processos que alteram a fisionomia dos lugares. Na via da abordagem sistêmica podemos estabelecer um ponto de partida para a leitura da paisagem, considerando os fluxos de matéria e energia entre solo, subsolo, cobertura vegetal, fauna, hidrografia, clima e os artifícios humanos. 
Conforme Castro et. al.:

A paisagem é constituída por um conjunto de elementos, dos quais fazem parte os processos naturais e a utilização que deles fazem os grupos humanos, apresentando determinada organização e estrutura espacial. Qualquer uma das componentes existentes apresenta clara dependência em relação a um todo, resultando sempre da sua interacção no tempo e no espaço. Desta forma, é a materialização das componentes físicas e humanas que reveste de sentido aquilo a que chamamos paisagem e que constitui, no fundo, o território. (Castro et. al., 2008, p. 139)

Assim, temos uma entrada direcionada ao entendimento de uma das dimensões da paisagem e que, por sua vez, pode ser tomada a partir dos diferentes arranjos entre seus elementos materiais. Há a possibilidade de defini-la como o conjunto de formas produzidas pelo homem mais os componentes naturais que se apresentam desde 0 entorno imediato a um observador até o limite mais longínquo do seu campo de visada. Trata-se de uma composição visual que abarca certa organização do espaço e captura algumas particularidades que permitem montar esquemas explicativos sobre as dinâmicas do meio e os níveis de antropização.

Uma equipe da Universidade de Toulouse-Le Mirail, com o professor G.Bertrand à frente (Husbschman, Carcenac, Bertrand etc.), definiu a paisagem, em 1968, da seguinte forma: "É uma porção do espaço caracterizado por um tipo de combinação dinâmica e, portanto, instável, de elementos geográficos diferenciados - físicos, biológicos e antrópicos - que, ao atuar dialeticamente uns sobre os outros, fazem da paisagem um conjunto geográfico indissociável que evolui em bloco, tanto sob o efeito das interações entre os elementos que a constituem como sob o efeito da dinâmica própria de cada um dos elementos considerados separadamente". Essa definição, que segue a linha do pensamento de A. Cholley, corresponde, na realidade, ao conceito do atual sistema. Estabelece as unidades de paisagens complexas em três níveis: o meio físico, os ecossistemas e a intervenção humana, e define uma perspectiva dinâmica em diferentes graus de evolução. Nesse aspecto, G. Bertrand apóia-se na teoria da bioresistasia do edafólogo Erhart, que define os indicados conceitos em relação à constituição e destruição do solo. Bertrand distingue entre geossistemas em biostasia, 
recobertos de densa vegetação, estáveis, e geossistemas em resistasia, nos quais, ao estar a litologia a descoberto, predomina a morfogênese, contrária à edafogênese e à colonização vegetal. Alguns geossistemas se encontram em resistasia por causas naturais, e a morfogênese corresponde, então, à própria do clima e do ambiente associado a um determinado tipo de forma e de vegetação, naturalmente pobre. Outros resultam de uma degradação antrópica, e são em realidade regressivos.

BERTRAND chama a atenção para o fato de que "a conceitualização unívoca (exemplo: ecossistema) que até hoje prevaleceu permitiu realizar progressos essenciais, porém ainda insuficientes. A ideia consiste em prever várias "entradas" possíveis em um mesmo sistema especulando sobre finalizações possiveis e as hierarquias internas". E, então, propõe um sistema com três "entradas" teleológicas: 1. A fonte/source ou a "entrada" naturalista: o Geossistema; 2. O recurso/ressource ou a "entrada" socioeconômica: o Território; 3. A identidade/ressourcement ou a "entrada" sociocultural: a Paisagem.

Bertrand (2002) explicita, de forma bastante didática, o sistema metodológico fundado sobre estes três conceitos espaço-temporais:

- O Geossistema,

- O Território,

- A Paisagem.

- O geossistema representa o espaço-tempo da natureza antropizada. É a "fonte" (source) jamais captada, tal qual ela escorre da vertente, mas que pode ser já poluída.

- O território, fundado sobre a apropriação e o "limitar/cercar", representa o espaço-tempo das sociedades, aquele da organização política, jurídica, administrativa e aquela da exploração econômica. É o "recurso" (ressource) no tempo curto e instável do mercado.

- A paisagem representa o espaço-tempo da cultura, da arte, da estética, do simbólico e do místico. Ela é o ressourcement de tempo longo, patrimonial e identitário.

De inspiração sistêmica, o geossistema se diferencia claramente do ecossistema pelo fato da sua territorialização e da sua antropização, ou seja, o geossistema é um conceito não somente espacializado, mas também territorializado, isto é, com toda uma carga de história humana. 
Enfim, para não levantar qualquer equívoco, é preciso insistir sobre o fato de que este conceito antrópico não é em nada um conceito social. Ele (o geossistema) não tem por função explicar a sociedade na sua relação com o território, mas de entender a fisionomia e o funcionamento do território sob o impacto da sociedade. Na sua configuração atual, o geossistema é ainda um conceito pouco desenvolvido, longe da maturidade científica do ecossistema. Mas ele deve evoluir e tornar-se uma das referências espaço-temporais para a pesquisa sobre o ambiente.

Nós procuraremos mostrar que, efetivamente, a paisagem pode ser um indicador pertinente das dinâmicas espaciais na interface das interações do social e do natural, notadamente onde os terrenos de estudo são de difícil apreensão, em razão da rapidez das mudanças, da carência de dados confiáveis e dos incontornáveis problemas logísticos de coleta de informações locais, devidos ao isolamento e à imensidão desses territórios.

A paisagem pode ser considerada como uma marca dos processos de antropização ligados a diferentes categorias de atores (colonos chegados recentemente, agricultores proprietários de suas terras, pequenos e grandes proprietários rurais, MST, agroindústria da cana-de-açúcar etc.) de um meio dado? Pode-se, em conseqüência, identificar sobre cada terreno de estudo paisagens-indicadoras (unidades de paisagens) que informem, por meio de sua composição e de sua estrutura, sobre os mecanismos de funcionamento próprios a cada geossistema observado?

A espacialização das paisagens-indicadoras pelo tratamento de imagens de satélite contribui para a apreensão de um nível de informação regional confiável e coerente para a produção de cartas que permitem compreender e avaliar o estado dos territórios e acompanhar suas mudanças?

Enfim, a identificação de paisagens-indicadoras e a espacialização cartográfica constituem um nível inicial de observações das dinâmicas paisagísticas. Em que medida ela pode ser considerada como um ponto de partida satisfatório e suficiente para a realização de diagnósticos paisagísticos temáticos? 
A paisagem-indicadora torna-se então paisagem-integradora, pois ela permite 0 cruzamento de diferentes informações orientadas segundo uma problemática específica própria a cada dinâmica regional. Este primeiro passo em direção ao melhoramento dos conhecimentos dos meios e das sociedades que os habitam constitui um dos suportes das proposições para a ajuda da decisão em matéria de políticas de desenvolvimento sustentável.

\subsection{Objetivos}

Em relação a esta dupla finalidade, a pesquisa comporta três objetivos complementares, que correspondem a diferentes etapas metodológicas.

- 1 - Identificação de paisagens-indicadoras para um melhor conhecimento territorial na interface natureza-sociedade.

Trata-se de mostrar como a entrada pelas paisagens pode servir para analisar o contínuo espacial segundo um ponto de vista comum, que atenda tanto às ciências da natureza como às ciências sociais e, por conseqüência, permita construir uma tipologia paisagística que possa servir de linguagem de referência entre as diferentes disciplinas associadas (geografia, pedologia, botânica, teledetecção,...). Esta categorização espacial apresenta o interesse de centrar as análises em torno dos mesmos objetos de observação, de facilitar os cruzamentos e complementos de informações e de determinar paisagens indicadoras das dinâmicas espaciais. Tudo isso para melhorar os conhecimentos sobre os territórios nas trajetórias da evolução contrastada em função das variáveis socioambientais que tem localmente o desenvolvimento sustentável.

- 2 - A espacialização das informações para mise en place de "observatórios" ${ }^{2}$ das dinâmicas paisagísticas.

A detecção de paisagens indicadoras sobre as imagens de satélite tem por objetivo produzir cartas que ofereçam uma visão global e homogênea tanto no tempo como no espaço destes territórios em constante evolução. A ideia é posicionar os

\footnotetext{
2 Os "observatórios" são, na verdade, áreas georreferenciadas - em áreas rurais - para efeito de acompanhamento mais sistemático de suas dinâmicas socioambientais, a partir de imagens de satélite e de observações in locus.
} 
"observatórios" para acompanhar os meios agrícolas ou outros e seus contextos ambientais na escala regional das paisagens. Este nível está relacionado com as unidades de gestão territorial às quais se aplicam as políticas públicas e os projetos de desenvolvimento.

- 3 - A construção de diagnósticos paisagísticos temáticos adaptados às variáveis próprias do terreno de estudo, em vista de proposições de desenvolvimento sustentável específico. Está aqui a questão de "regular" os "observatórios" de maneira a focalizar a produção de informações espacializadas para as questões socioambientais que se colocam para cada região de estudo.

Para melhor compreender os mecanismos de funcionamento, restituir rapidamente estes resultados via um "observatório" e os mobilizar nos diagnósticos territoriais atualizados de modo a ajudar na formulação de projetos de desenvolvimento regionais apoiados na sustentabilidade.

\section{O sudoeste do Pará/Novo Progresso: eixo da BR-163}

É bom lembrar que o projeto de ocupação e colonização, pilotado pelo Instituto Nacional de Colonização e Reforma Agrária/INCRA, no início da década de 1970, ao longo da BR-163, no sudoeste do Pará, definiu duas grandes categorias de uso da terra:

- de Santarém - confluência do rio Tapajós com o rio Amazonas - até a ponte de concreto sobre o rio Aruri: colonização social, ou seja, assentamento de colonos em lotes de 100 hectares.

As agrovilas implantadas ao longo da BR-163, a intervalos de $10 \mathrm{~km}$, em que estão assentadas as moradias dos colonos, uma escola primária, uma capela ecumênica, um pequeno armazém, uma farmácia e uma clínica, dirigidas por Assistente Rural. Muitas dessas agrovilas retratam a frustração do Projeto INCRA, e dos próprios colonos, e se encontram em estado de total pobreza e esquecimento dos gestores públicos. (PASSOS, 2007, p.112); 
- da ponte sobre o rio Aruri até a Serra do Cachimbo/divisa dos estados do Pará e Mato Grosso. Nessa segunda parcela do território foram assentados os grandes projetos agropecuários.

É no contexto do desenvolvimento das grandes vias de comunicação da Amazônia brasileira que um amplo campo territorial foi aberto aos colonizadores. A BR-163, aberta ao longo da floresta e dos cerrados, liga Cuiabá no Mato Grosso a Santarém no Pará (Figura 1). Esta via serviu de "porta de entrada" para a ocupação do Nortão do Mato Grosso e para o Sudoeste do Pará. A "homogeneidade" das condições naturais desse território, interrompida tão somente pela presença dos rios e da Serra do Cachimbo, favoreceu a concentração do povoamento.

A imagem de satélite de 1975 revela somente pequenas áreas de desmatamentos realizados nas proximidades da BR-163, desenhada como um corredor no meio da vegetação (Figura 1). Apesar de essas terras serem consideradas virgens, pelas companhias colonizadoras, observam-se indícios claros da presença humana nas margens do rio Teles Pires que são visivelmente anteriores à implantação da rodovia (presença de índios e/ou de posseiros). Ao contrário, mais a oeste desta imagem, parece não existir nenhum sinal de habitat humano. Dez anos após a chegada de migrantes, a partir de muitos projetos públicos e privados, transformaram este mesmo espaço.

Sobre a imagem Landsat MSS de 1975, aparecem sete novos municípios num raio de aproximadamente 85 quilômetros. Sinop detém quase que a metade desse território, enquanto que os outros seis dividem os cinquenta quilômetros restantes (Figura 1).

A imagem Landsat de 1986 permite notar a importância das alterações durante uma dezena de anos e as diferenças do avanço da frente pioneira. Sobre este pequeno extrato da imagem, é notável a disparidade na organização rural: a conquista aqui é diferente. Os dois conjuntos de desmatamentos maiores: um ao Norte (Colider) e outro ao Sul (Sinop) colocam em evidência as diferenças da conquista espacial. Uma privilegia a conquista por pequenas manchas dispersas e, a outra, grandes manchas. As disparidades espaciais, ou seja, o desenvolvimento dessas novas entidades administrativas dependem da gestão dos organismos colonizadores e de seus 
responsáveis, uma vez que os projetos recebem colonos diferenciados quanto ao local de origem e quanto à capacidade de investimento.

As infraestruturas das rodovias têm uma relação direta com a multiplicação dos projetos de colonização, da chegada dos colonos, dos investimentos realizados no domínio da agricultura e da criação de municípios. Este processo é representativo do caminhamento da sociedade brasileira e as conseqüências se manifestam no nível da organização espacial do país. Se a frente pioneira é ainda possível, quem/o que poderia frear sua evolução?

Figura 1 - Evolução dos desmatamentos ao longo do eixo da BR-163

(objetivando a prioridade da parcela do território selecionado para este artigo, vamos destacar o trecho compreendido entre a Serra do Cachimbo e Novo Progresso/PA).

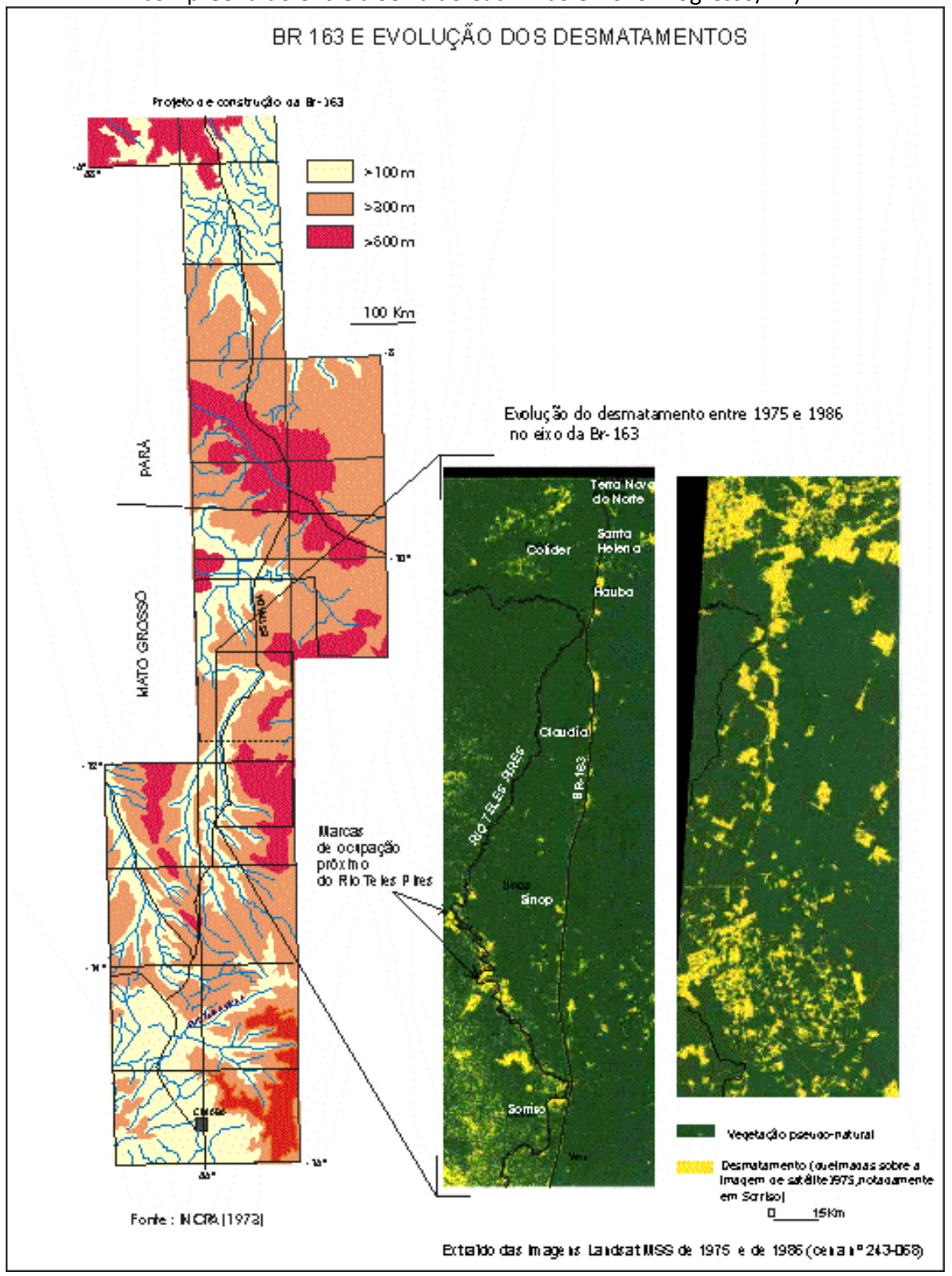


Figura 2 - O trecho Novo Progresso a Cachimbo é o menos povoado ao longo de toda a BR-163, notadamente os primeiros cem quilômetros que antecedem a divisa com o estado do Mato Grosso, por várias razões: (a) presença da base do Exército; (b) topografia movimentada; (c) presença de várias áreas de reserva indígena; (d) solo extremamente arenoso (dunas continentais), entre outras.
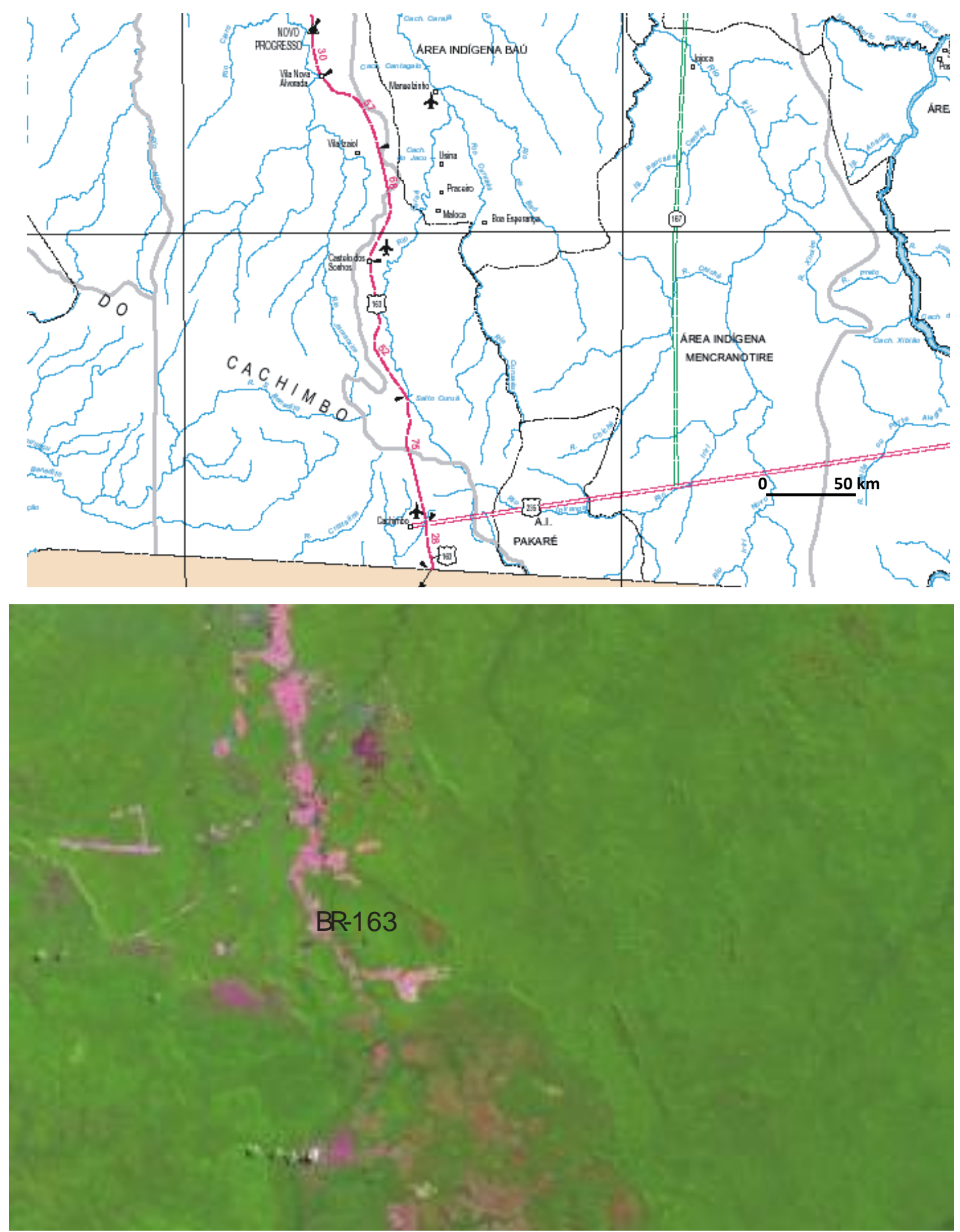


\section{Resultados}

O estudo sob a perspectiva de "paisagem-indicadora" requer um sistemático e duradouro processo de observação/monitoramento que, infelizmente, os projetos de curta duração (dois anos) não favorecem. Portanto, os resultados alcançados, apesar de relevantes, notadamente em termos de procedimento metodológico, são frágeis quando se objetiva diagnosticar-prognosticar os impactos das políticas públicas e, ainda, da ação dos agentes privados. Um exemplo da fragilidade dessa "abordagem em tempo curto" está na provável dinamização do uso do solo na área de influência da BR163 após a pavimentação asfáltica aplicada sobre o leito dessa rodovia a partir do ano de 2011.

Nesse momento, vamos nos ater a dois resultados significativos da nossa metodologia de pesquisa: (a) a evolução do uso do solo no eixo da BR-163 e (b) os pontos georreferenciados.

\section{A dinâmica do uso da terra/uso do solo no sudoeste do Pará/Eixo da BR-163}

Figura 3 - Uso da terra no sudoeste do Pará/eixo da BR-163: as manchas de desmatamentos mais significativos (em vermelho) estavam "restritas" ao leito da rodovia e aos projetos agropecuários na Serra do Cachimbo - (1990).

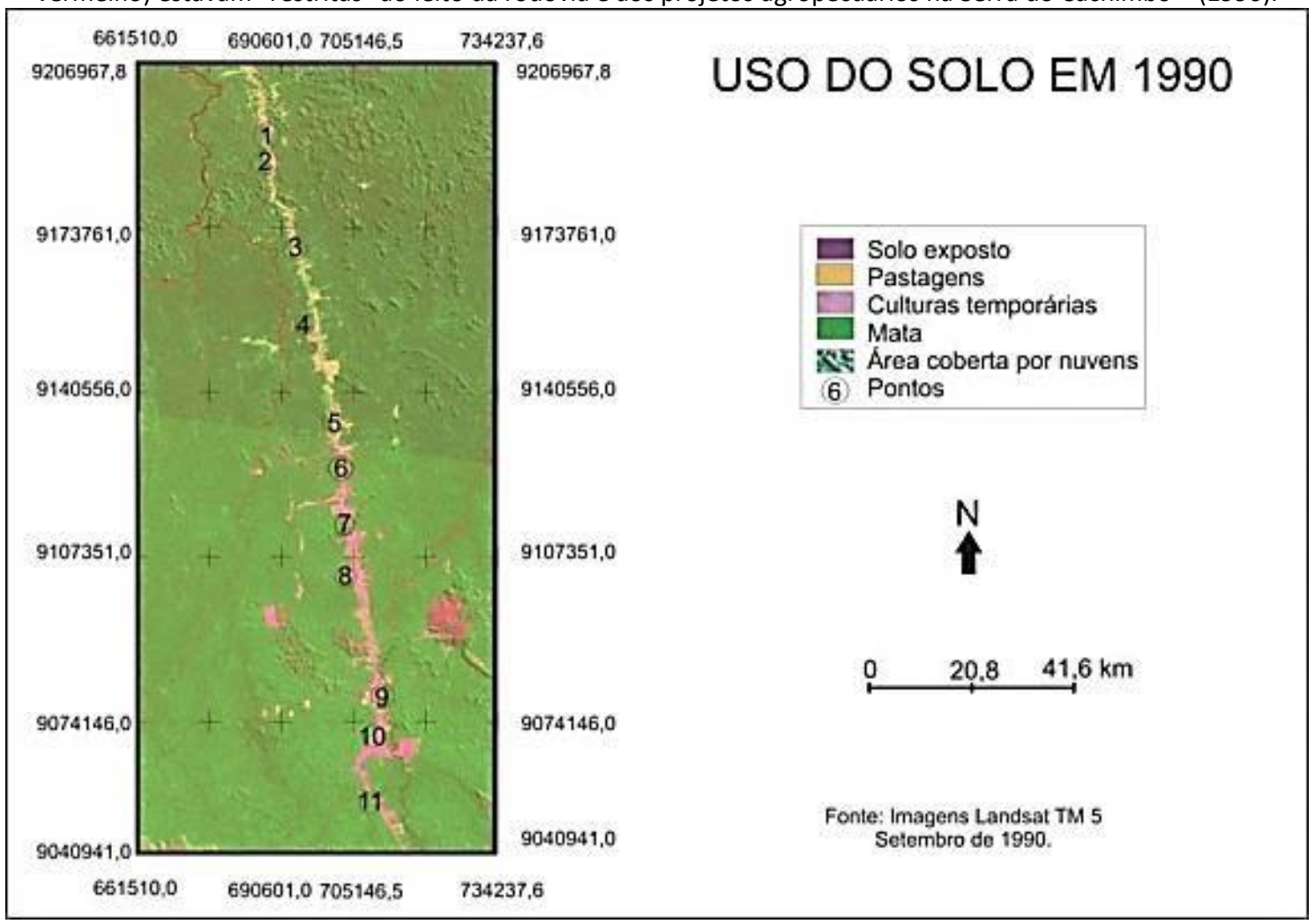


Figura 4 - Uso da terra no sudoeste do Pará/eixo da BR-163: pequenas áreas de desmatamentos recentes (manchas em amarelo) são constatadas, notadamente nas proximidades da cidade de Novo Progresso localidade com maior concentração de serrarias - (1995).

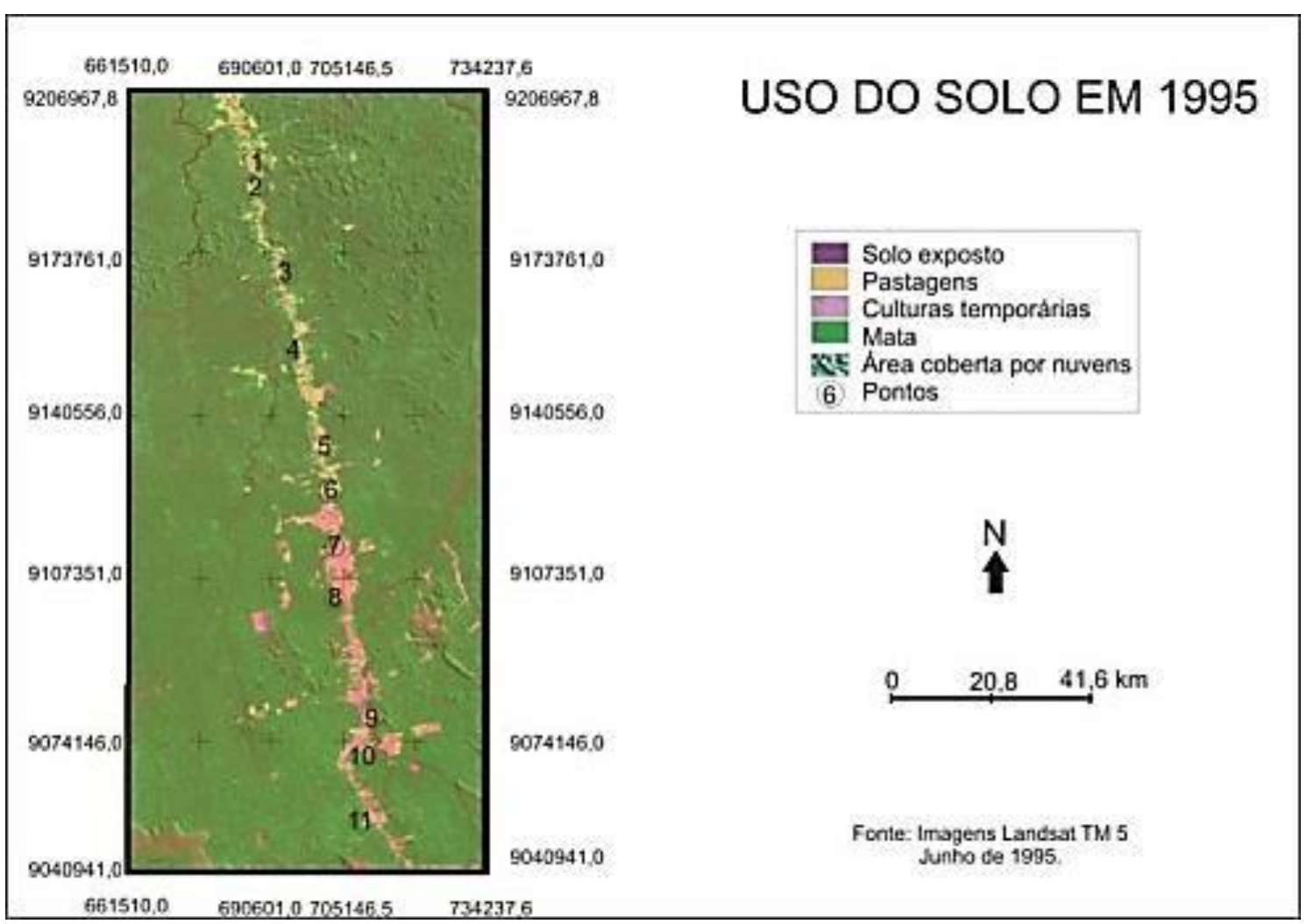

Figura 5 - Uso da terra no sudoeste do Pará/eixo da BR-163: pequenas áreas de desmatamentos recentes (manchas em amarelo) estão mais dispersadas e afetam praticamente toda a área de influência da rodovia - (2000).

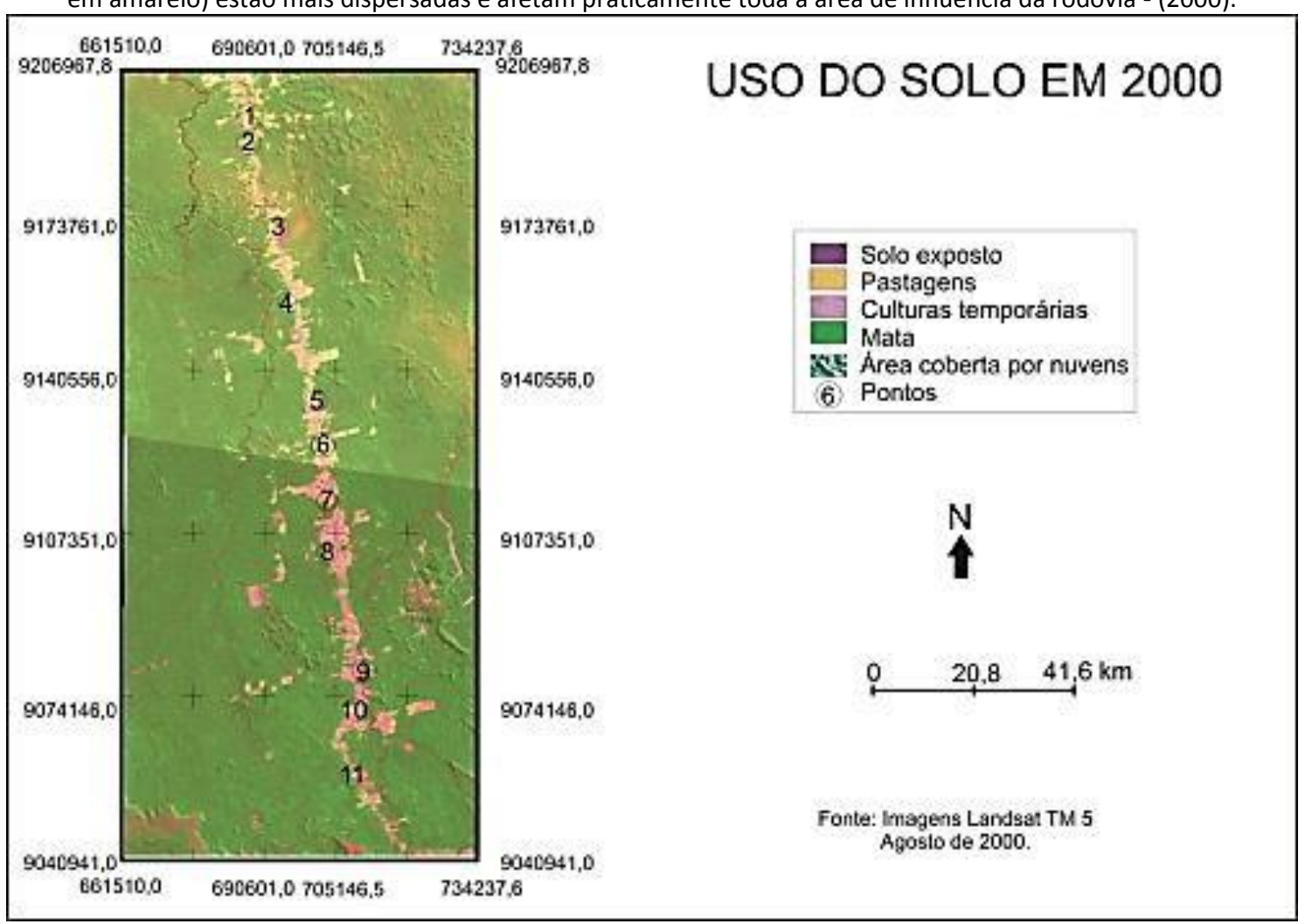


Figura 6 - Uso da terra no sudoeste do Pará/eixo da BR-163: as áreas desmatadas ganham proporções alarmantes, apesar do incremento das ações dos órgãos federais fiscalizadores - (2005).

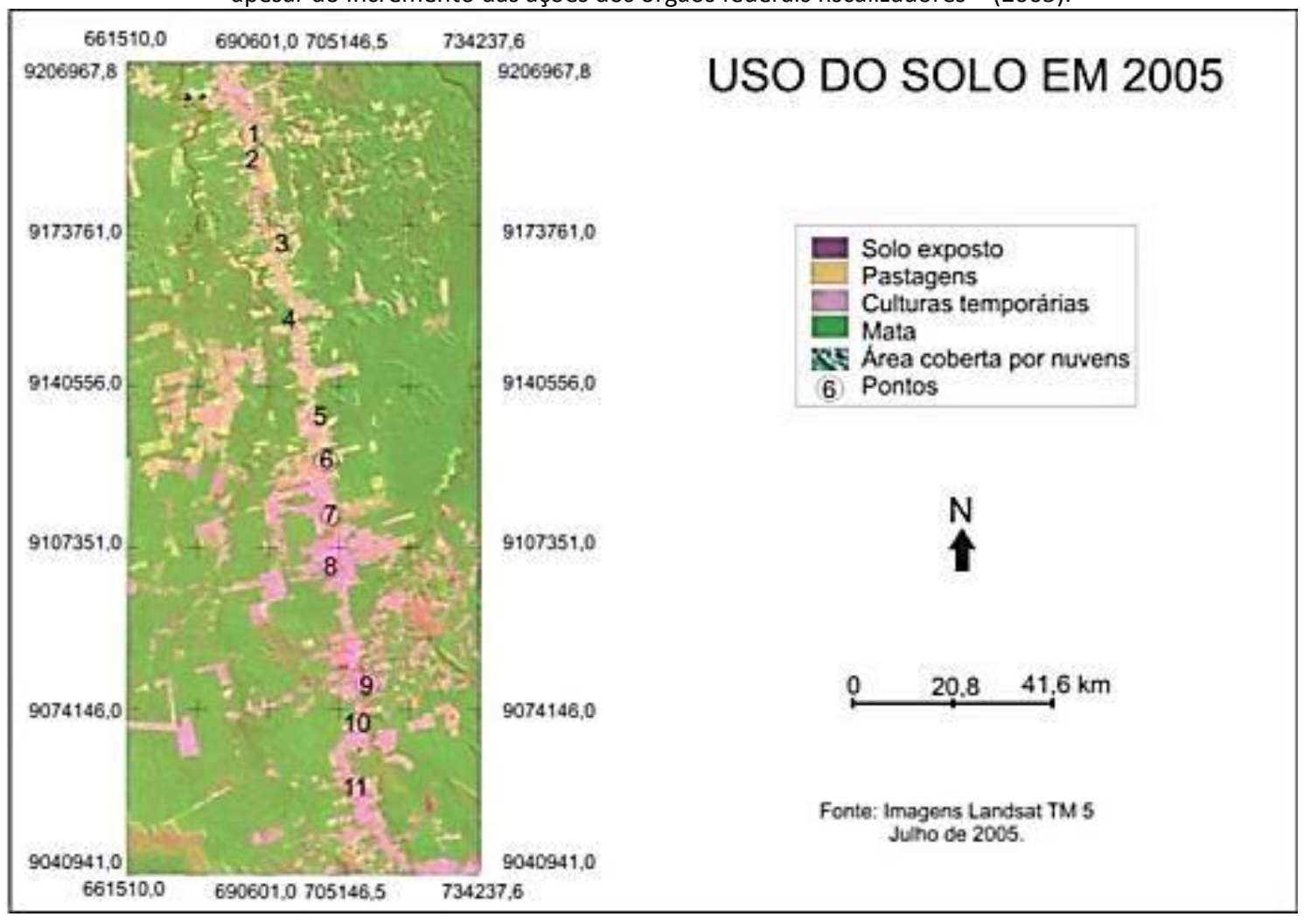

Figura 7 - Uso da terra no sudoeste do Pará/eixo da BR-163: apesar das ações do Governo Federal (Operação Curupira, por exemplo) o desmatamento se generaliza - (2010).

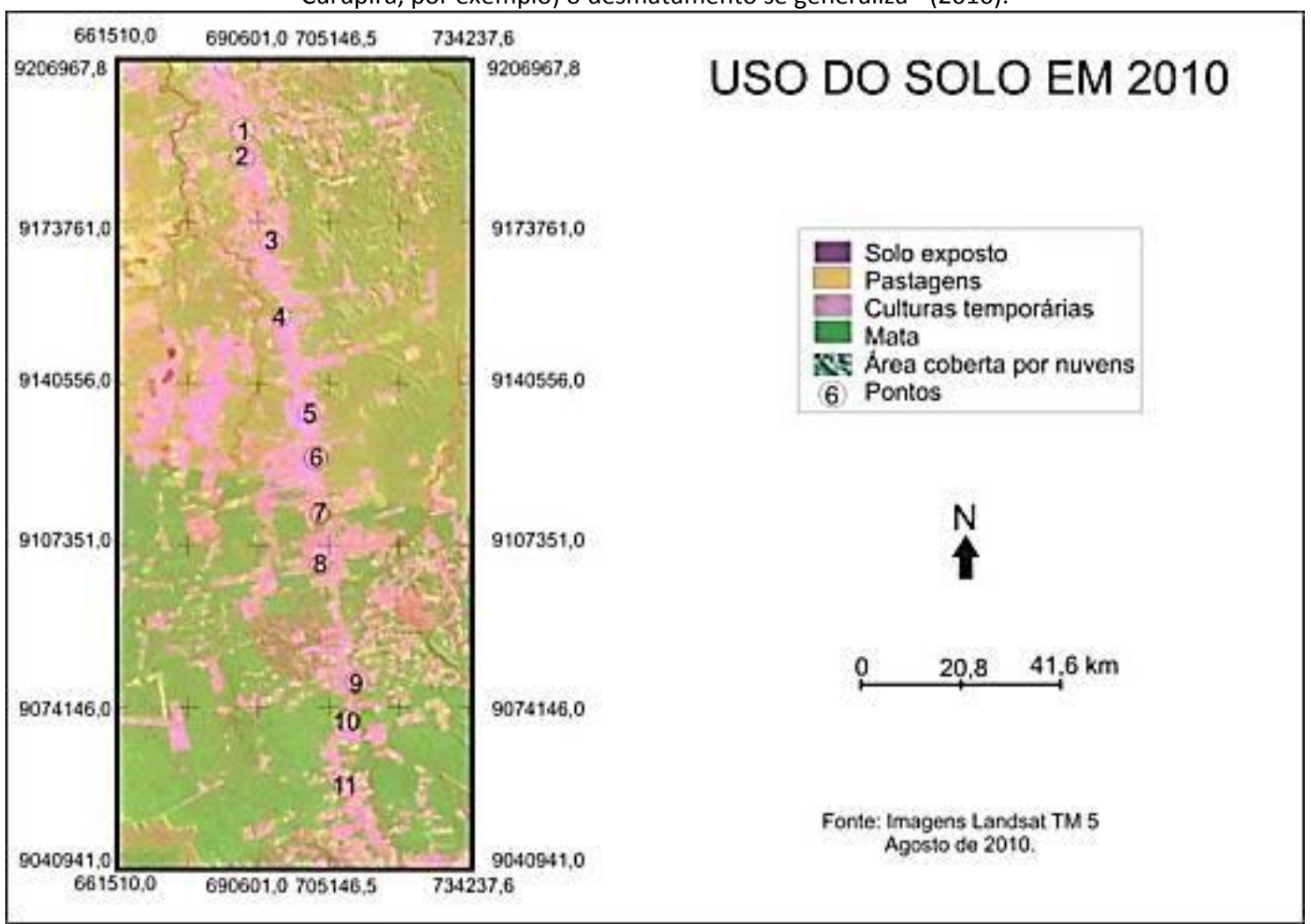


Os geótopos georreferenciados - instrumentos de observações sistemáticas das mudanças socioambientais:

Figura 8 - Geótopo 1 - Entrada da currutela de Castelo de Sonhos/PA

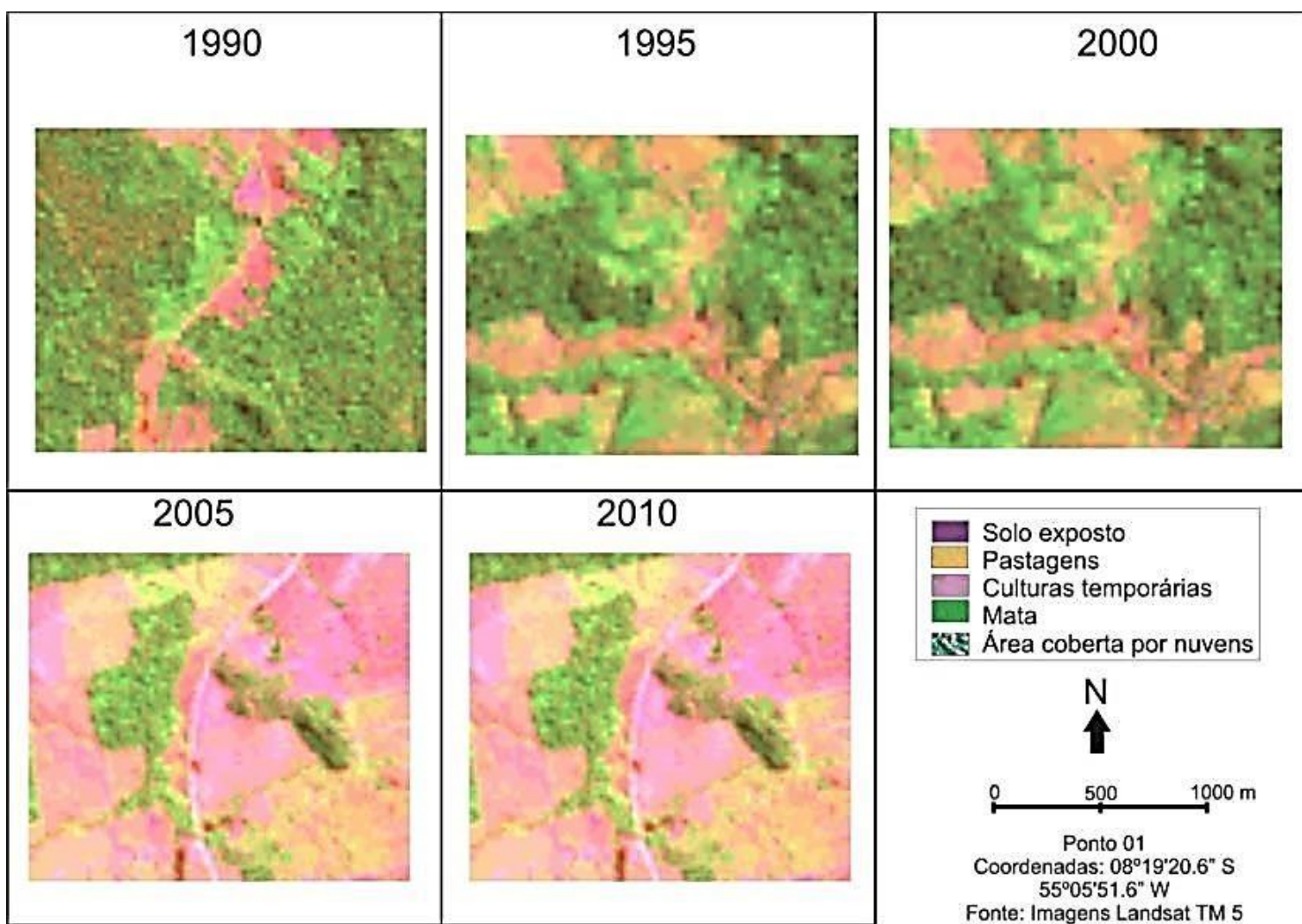

Foto referente ao Geótopo 1: o poste de itaúba foi mantido por exigência do pioneiro Jones Bernat, pois o considera um símbolo da fase inicial do povoamento da currutela de Castelo de Sonhos. Passos: 07/09/2011.

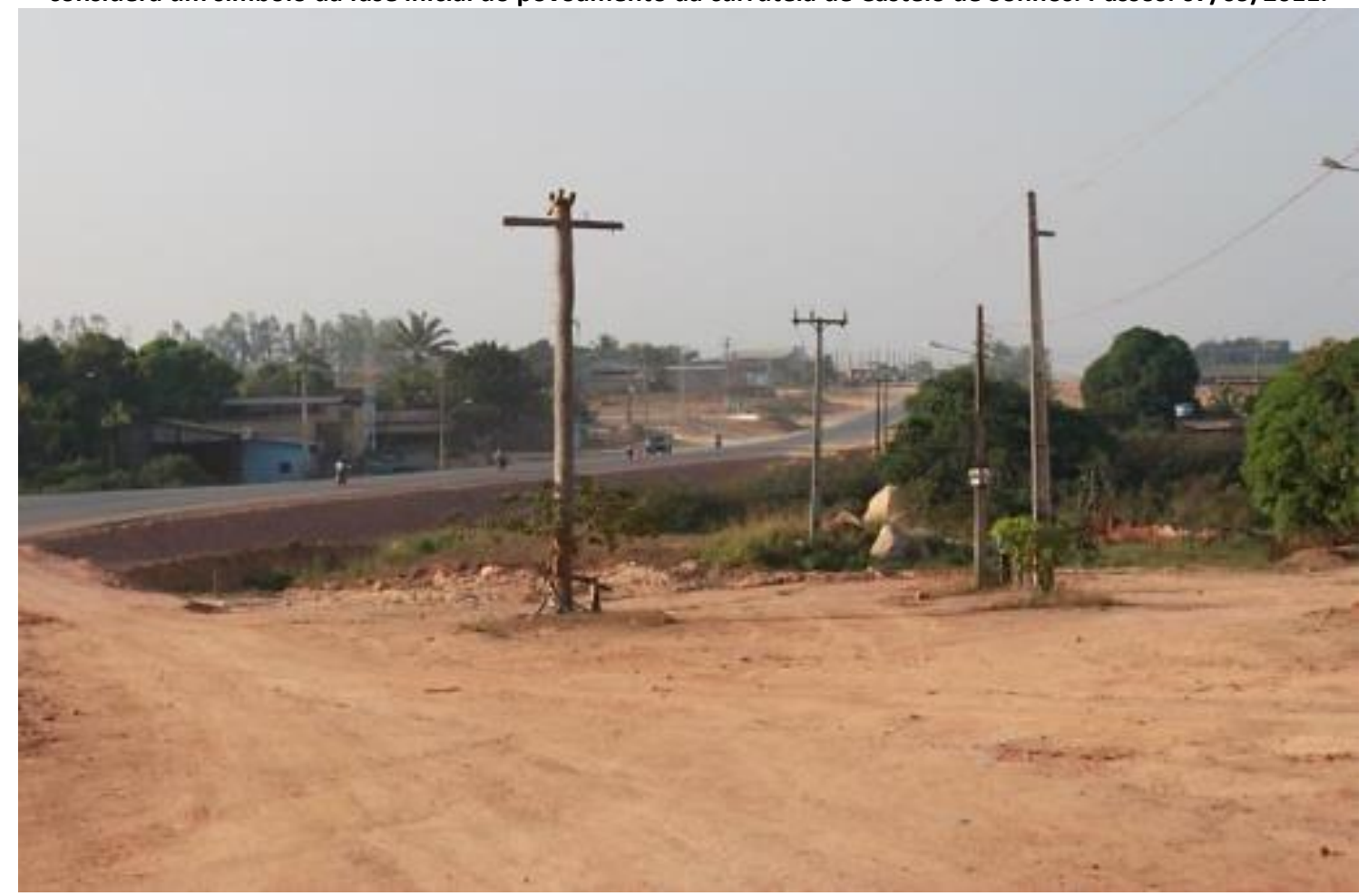


Figura 9 - Geótopo 05 - Fazenda Santa Alice/Sudoeste do Pará

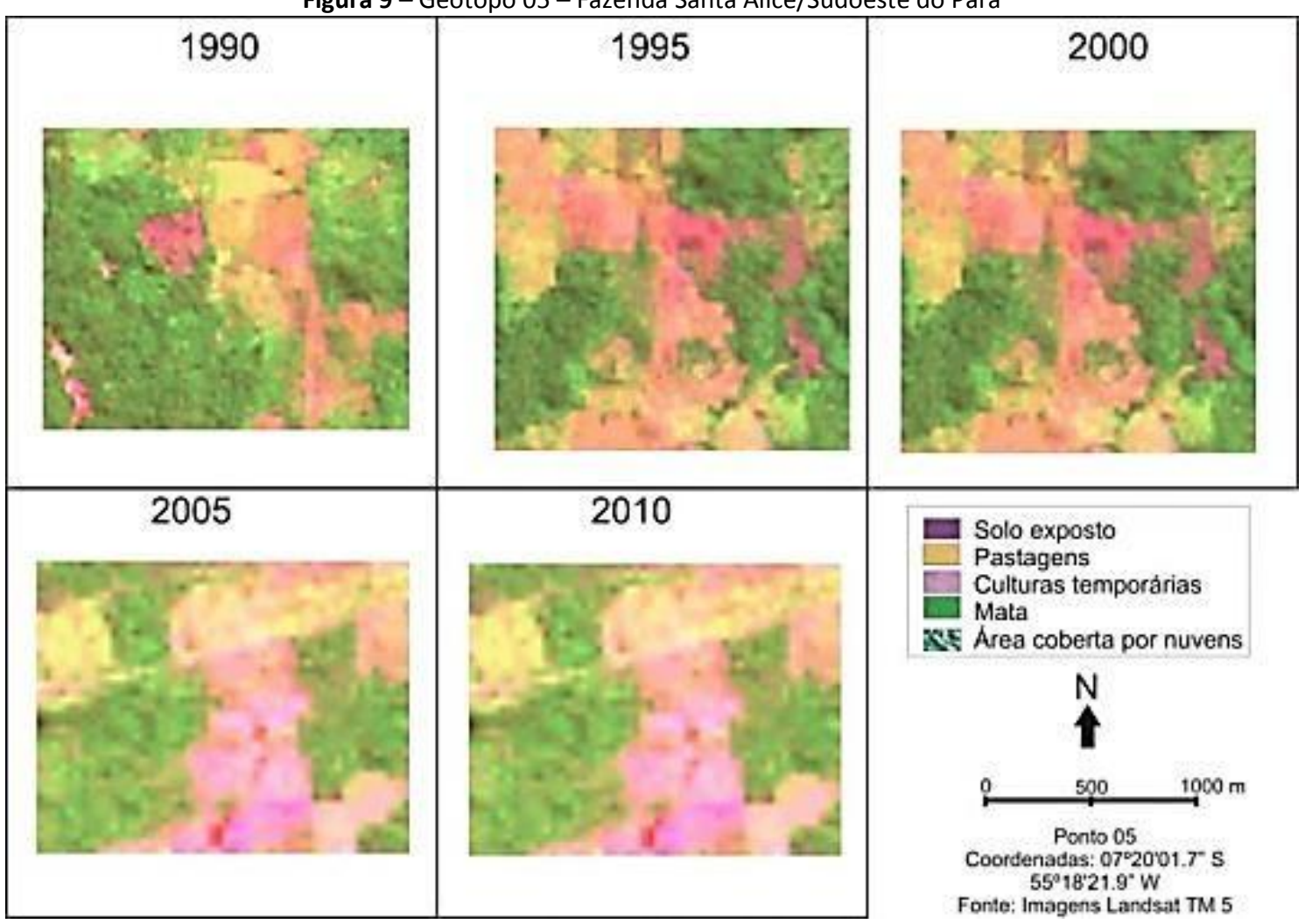

Foto referente ao Geótopo 05: Fazenda Santa Alice - Ponto 5: 07920’01.7" S - 55018'21.9” W - Altitude: 247m. PASSOS: 08/09/2011.

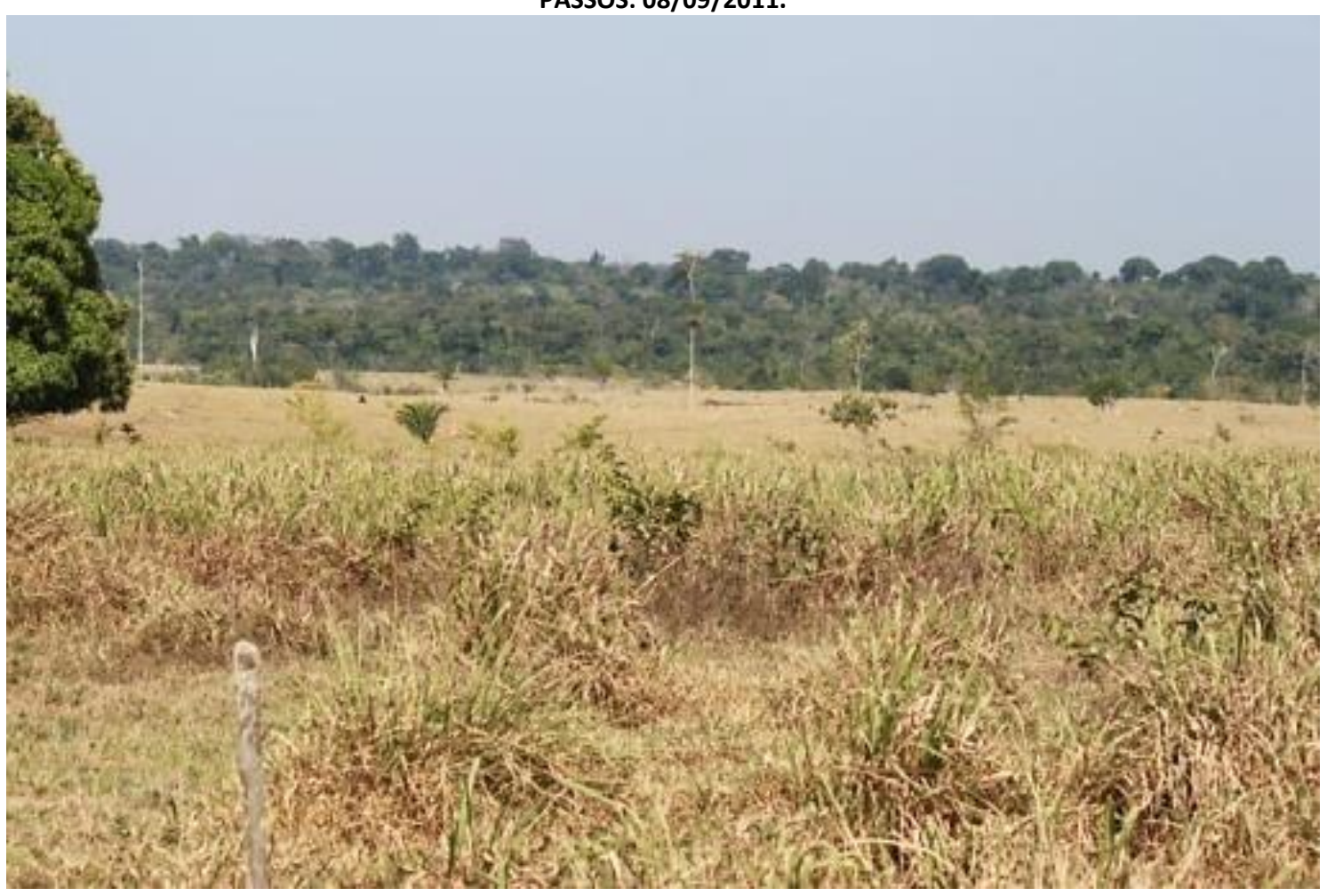


Figura 10 - Geótopo 06 - "região" de morraria com matacões de granito/gnaissico/Sudoeste do Pará

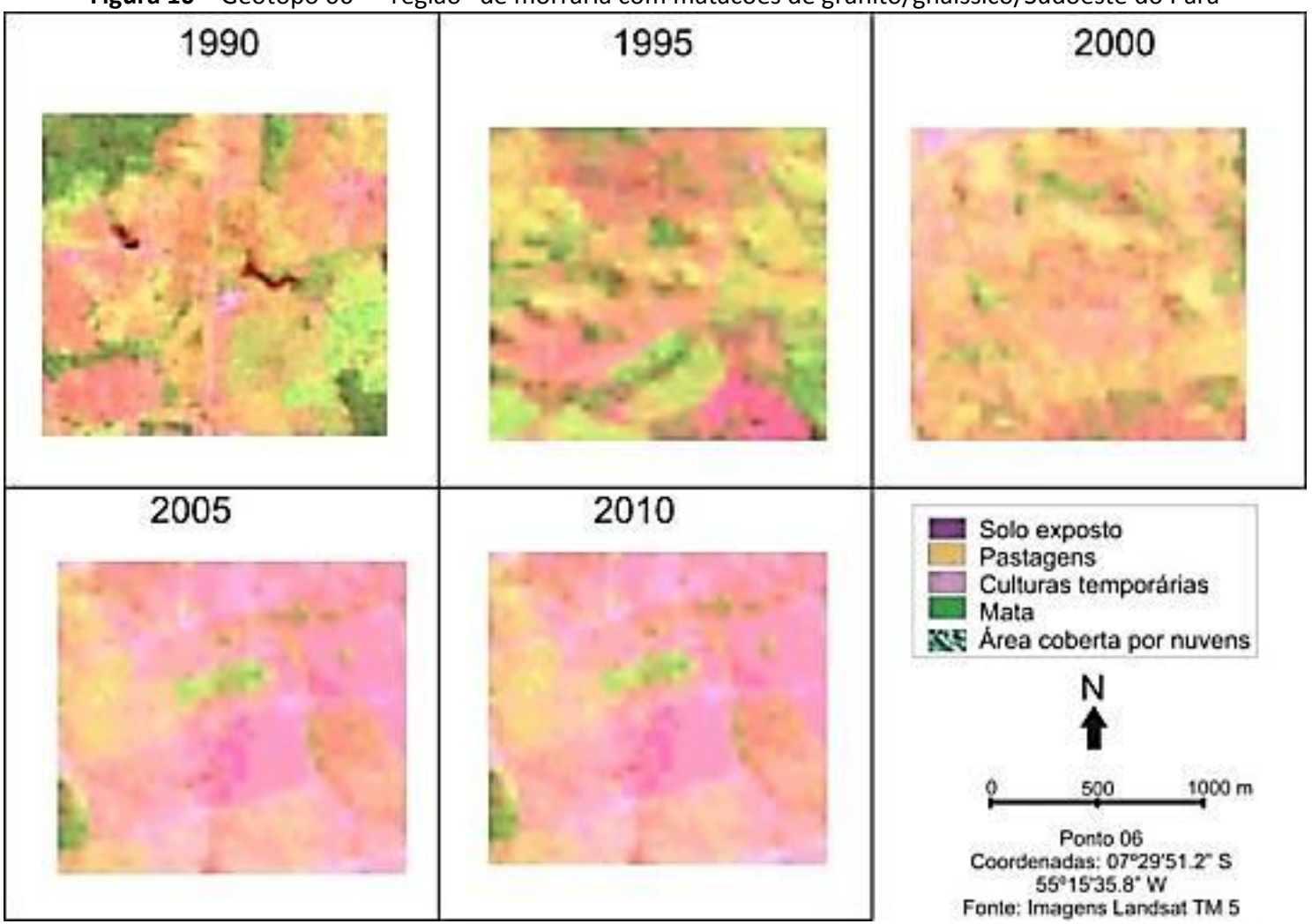

Foto referente ao Geótopo - Ponto 6: 0729'51.2" S - 5515’35.8” W - Altitude: 234m. Passos: 08/09/2011.

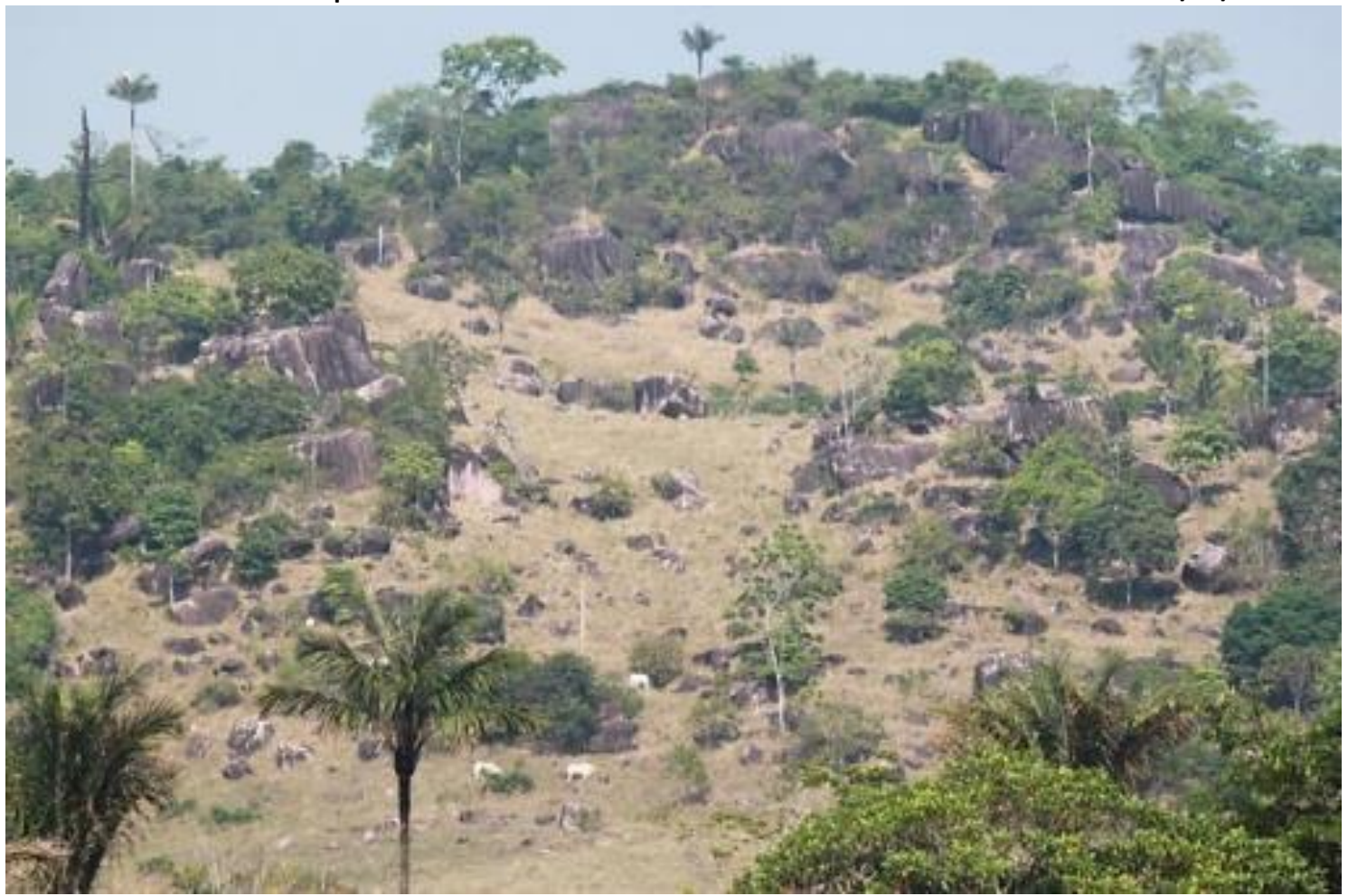




\section{Considerações finais}

As sucessivas mudanças dos "planos de desenvolvimento", ao sabor das conjunturas políticas e econômicas, contribuíram para a falência da grande maioria dos projetos de colonização. A nossa conclusão está voltada para algumas variáveis que apontam para a insustentabilidade do modelo de desenvolvimento regional:

- Um modelo excludente: no esforço de escolher uma imagem que seja reveladora do ambiente da fronteira atual, diríamos que esta imagem é a da "exclusão". A fronteira se organiza em função dos mercados e das conjunturas momentâneas; ela alterna fases de prosperidade com fases de depressões, de regressões. O sucesso no aumento da produtividade, não é revertido em benefício do produtor e nem mesmo do meio ambiente. A fronteira agrícola continua avançando, mesmo que esta mobilidade não tenha respaldo numa possível necessidade de produzir mais. Há muito mais áreas desmatadas do que as áreas efetivamente ocupadas economicamente.

- Um modelo produtivista - após vinte anos é o agronegócio que, notadamente no Mato Grosso, conhece o mais forte desenvolvimento, sustentado pela necessidade do Brasil obter divisas a partir de produtos exportáveis como a soja. A superfície plantada aumentou de 43\% no Brasil, entre 1980 e 1990 e, em mais de 150\% no Mato Grosso.

- Desflorestamento e fragmentação contínua das florestas amazônicas - os estudos recentes do Instituto Nacional de Pesquisas Espaciais (INPE, 2000, 2002, 2005), no âmbito dos quais o desmatamento é qualificado a partir da interpretação de imagens de satélites, mostram que a área total de floresta tropical derrubada na Região Amazônica aumentou para $631 \mathrm{mil} \mathrm{km}^{2}$ em 2003. Isso equivale a 15,4\% da área coberta pela floresta tropical na Amazônia Legal, calculada por Skole e Tucker (1993) em 4,1 milhões de $\mathrm{km}^{2}$. Estimativas oficiais do governo divulgam que $26,1 \mathrm{mil} \mathrm{km}^{2}$ teriam sido desmatados entre agosto de 2003 e julho de 2004.

A área de floresta afetada por atividades humanas a cada ano é muito maior do que os dados mostrados pelo programa de monitoramento do INPE, devido aos incêndios de superfície que fogem do controle e se expandem para a floresta primária. Eles podem destruir de $10 \%$ a $80 \%$ da biomassa da superfície, mas dificilmente são detectados por 
imagens de satélite. Os incêndios de superfície podem afetar o dobro da área de desmatamento e até áreas maiores nos anos de secas severas (Nepstad et al., 1999).

- Atividades madeireiras - Grupos de madeireiros danificam gravemente de 10 a 15 mil $\mathrm{km}^{2}$ de floresta por ano, que não estão incluídos nas estatísticas de desmatamento (Nepstad et al., 1999), tendo em vista que a extração de madeira se espalha para grandes áreas da região amazônica sem nenhuma regulamentação. Em 2001, 189 milhões de $\mathrm{m}^{3}$ de madeira em tora foram apreendidos, 78 \% a mais que em 2001 (Folha de São Paulo, 11.6.2002). Nos projetos, entendidos como economicamente necessários, deve haver uma escala de classificação totalmente nova, sobre o que significa "desenvolvimento", como custos e fatores de tempo: os custos ecológicos e sociais, diretos e indiretos, e custos subsequentes devem ser incluídos nos projetos e ser testados no sentido de um efeito positivo a médio e longo prazo. A transversalidade de políticas e práticas não está ocorrendo nas frentes de expansão da Amazônia, onde se observa uma retomada e aceleração na apropriação de terras públicas, na degradação das florestas por ação de madeireiros e na expansão da pecuária para amansar o solo antes da expansão da soja.

Após o fracasso das iniciativas do governo para diminuir as formas predatórias de exploração da floresta (Lele et al., 1999), surgiram em 1997 os certificados de silvicultura baseados em padrões sociais e ambientais, com o objetivo de promover a gestão florestal sustentável (Leroy/Fatheuer, 1996). Entre as iniciativas de certificação, o Forest Stewardship Council (FSC) ganhou reconhecimento significativo. Até hoje, apenas um pequeno número de empresas recebeu o selo do FSC no Brasil (Scholz, 1999). A demanda por certificados dependerá da consciência do consumidor final de madeiras e dos regulamentos do mercado e do comércio internacional.

A Amazônia está na mídia mundial... Fala-se muito da floresta, da biodiversidade... Fala-se pouco do homem, dos povos da floresta...

A Amazônia ainda é um território de conquista, muito presente na mídia, quase que desconhecida dos brasileiros. 
Ao longo das minhas várias viagens e das permanentes reflexões sobre as dinâmicas socioambientais e territoriais presentes no universo amazônico, debrucei-me sobre as imagens de satélite, mas, também, me nutri muito das narrativas dos colonos, do fotografar e ler a paisagem, das esperanças e das agonias de quem já era amazônico e de quem se tornou amazônico por opção ou por necessidade..., enfim, me nutri e gostei do tempero do pó-colorido da estrada... (Passos, M.)

Nessas últimas páginas da "BR-163: de estrada dos colonos a corredor de exportação", deixamos algumas reflexões:

- A possível e necessária conciliação entre desenvolvimento econômico e a preservação da Amazônia depende da inteligência brasileira, ou melhor, apesar da internacionalização da problemática amazônica, o território nos pertence..., apesar da baixa prioridade que os brasileiros, inclusive a universidade brasileira lhe dá;

- Não é pertinente/coerente o debate sobre a problemática amazônica que não contemple, prioritariamente, o homem que lá vive: a grande maioria dos colonos não é composta de intrusos, devastadores..., estes foram atraídos pelas políticas públicas, notadamente as políticas de ocupação e povoamento: não é justo e nem aceitável que a emergência de um novo contexto político (proliferação das ONGs, fragilidade do Estado etc.) ignore e penalize os colonos, os povos da floresta que lá chegaram para morar, trabalhar e sonhar...

- O desenvolvimento da Amazônia precisa mudar a ideologia, ou seja, passar do "desenvolvimento DA Amazônia" para o "desenvolvimento PARA a Amazônia", até porque, em 1980, a população humana da Amazônia era de apenas 5\% da brasileira e, atualmente, é de $10 \%$ do total do país, ou seja, são 25 milhões de brasileiros que não podem ser ignorados a cada novo modelo de desenvolvimento, a cada emergência de um novo contexto político, quer internacional, nacional ou regional;

- O desenvolvimento regional pressupunha dois tipos de ação: (a) Políticas Públicas de desenvolvimento de infraestrutura, de modo a ser coerente com o discurso de "homens sem terra" para "a terra sem homens", no quadro do Plano de Integração Nacional (PIN) e seleção de projetos de colonização agrícola coordenada pelo INCRA e 
de Pólos de Desenvolvimento; (b) Ação Privada baseada sobre investimentos em vários setores da economia, sobretudo na pecuária, extração de minerais e industrialização. Faltou consistência e coerência entre o discurso e a prática: os colonos ficaram órfãos de Pátria;

- É urgente que se faça um zoneamento que contemple tanto a preservação da floresta, quanto a exploração sustentável onde já está desmatado: o Estado brasileiro precisa ser mais inteligente e menos policial... Operações do tipo Curupira não são pedagógicas, se prestam mais para tumultuar as atividades socioeconômicas: é prepotência jogar no mesmo balaio todos os madeireiros, por exemplo; muitos deles reclamam da falta de orientação dos órgãos federais, estaduais e municipais e, claro, do custo que a corrupção acresce ao produto final. Muita devastação é consumada mais por falta de um trabalho pedagógico dos órgãos de fiscalização do que pela má fé dos agentes sociais;

- O asfaltamento da BR-163 deve ter prioridade maior: não é aceitável que toda produção de grãos realizada no Centro-Norte do país seja quase que totalmente exportada pelos portos marítimos do Sul e do Sudeste do Brasil: isto é pesadelo!

- A fase do "Sul Maravilha", quando os colonos chegavam para derrubar a mata e fazer riqueza rápida para retornar às regiões de origem, está quase que completamente superada! Observamos que o sentimento de pertencimento em relação ao mundo amazônico, apesar dos conflitos entre os vários atores e agentes, é muito forte, e tende para uma sedimentação irreversível.

- Atualmente, a fronteira está muito globalizada e fortemente dominada por decisões externas, por decisões do mercado internacional e das grandes trades - Cargil, Bunge, ADM. Mas o curioso é que, apesar dessa gestão amarrada à economia mundial, a fronteira se constrói de "dentro para fora", ou seja, ela está mais assumida e mais capitalizada, ciente das diferenciações relativas ao que acontece no Sul do país. Ela ainda avança em direção às novas áreas - sobretudo de floresta de transição, uma vez que as áreas de cerrado já foram quase que totalmente ocupadas; 
- Nunca é demais lembrar que a "ocupação dos espaços vazios", notadamente do Centro-Norte brasileiro, apesar de toda a propalada política de incentivos governamentais, dos incentivos fiscais etc., se dá a partir da compreensão de que o Estado Brasileiro só se constrói e se torna efetivamente presente a partir das "ações" e estas "ações", regra geral, estão à jusante da chegada dos pioneiros.

\section{Referências}

Béringuier, P.; Dérioz, P. \& Laques, A. É. (1999). "Les paysages français". Paris: ArmandColin.

Bertrand, C. \& Bertrand, G. (2002). “Une géographie traversière. L'environnement à travers territoires et temporalités". Paris: Arguments, 309 p.

Bertrand, C. \& Bertrand, G. (2009). “Uma geografia transversal - e de travessias. O meio ambiente através dos territórios e das temporalidades". Tradução: Messias Modesto dos Passos. Maringá: Massoni, 360 p.

Castro, E. et al. (2008). "Análise integrada da paisagem da raia central portuguesa". Pesquisa e Tecnologia Minerva, 5 (2), pp. 139-147. Disponível em: http://hdl.handle.net/10316/12157

Deffontaines, J.P. (1998). “Les sentiers d'un géoagronome”. Paris: Arguments, 360 p.

Donadieu, P. \& Périgord, M. (2005). “Clés pour le paysage” Paris: Editions Ophrys.

Grenier, Ch. (2000). “Conservation contre nature”. Paris: IRD, Coll. Latitudes 23.

Lele, U. et al. (1999). "Florestas em perigo: desafios da conservação com desenvolvimento." Uma avaliação do desenvolvimento florestal e da assistência do Banco Mundial no Brasil. Brasília: Banco Mundial, 145 p.

Leroy, J. P. \& Fatheuer, T. W. (1996). "Certificação florestal”, série Cadernos de Proposta 3, no 4, Rio de Janeiro: FASE/Sactes/DED, 52 p.

Nepstad, D. C., Moreira, A. \& Alencar, A. A. (1999). “A Floresta em Chamas: Origens, Impactos e Prevenção de Fogo na Amazônia". Programa Piloto para a Proteção das Florestas Tropicais do Brasil. Brasília, Brasi, 202 p. 
Passos, M. (2007) “A raia divisória - Eco-história”. Maringá: Eduem, 310 p.

Passos, M. (1988). "Biogeografia e paisagem”. Programa de Mestrado-Doutorado em Geografia FCT-UNESP/ Campus de Presidente Prudente - SP. Programa de Mestrado em Geografia UEM - Maringá - PR.

Skole, D.L. \& Tucker, C. J. (1993). "Tropical deforestation and habitat fragmentation in the Amazon - satellite data from 1978 to 1988". Science 260:1905-1910. 